\title{
Andrographolide modulate some toll-like receptors and cytokines expressions in HL-60 cell line
}

\begin{abstract}
Andrographolide, a labdane diterpenoid, is quantitatively the major bioactive secondary metabolite of Andrographis paniculata, which is now considered to be a promising therapeutic lead for prevention and cure of inflammatory disorders. Although involvements of Toll-like receptors (TLR) and diverse cytokines have been implicated in its modes of actions, as yet no reports on its effects on expressions of TLRs have appeared. Observations reported in this communication reveal that a non-cytotoxic concentration of andrographolide $(10 \mu \mathrm{M})$ completely suppresses TLR7 and TLR-8 expressions in HL-60 cells and has no effects on TLR-3 expressions in the cell line. Observed effects of this concentration of andrographolide on the expressions of three quantified cytokines (TNF- $\alpha$, IL-1 $\beta$ and IL-10) in HL-60 cells were not as pronounced as its suppressing effects on the two TLR expressions. These observations indicate that modulation of TLR-7 and TLR- 8 mediated inflammatory and anti-inflammatory cytokines expression are involved in the modes of actions of andrographolide.
\end{abstract}

Keywords: andrographolide, toll-like receptor expression, cytokine expression, HL60 cell
Volume 2 Issue 4 - 2015

\author{
Ajit Kumar Thakur,' Upendra Kumar Soni, ${ }^{2}$ \\ Geeta Rai, ${ }^{2}$ Shyam Sunder Chatterjee, ${ }^{3}$ Vikas \\ Kumar $^{1}$ \\ 'Department of Pharmaceutics, Indian Institute of Technology \\ (Banaras Hindu University), India \\ ${ }^{2}$ Department of Molecular and Human Genetics, Banaras Hindu \\ University, India \\ ${ }^{3}$ Stettiner Straße I, Karlsruhe, Germany
}

\begin{abstract}
Correspondence: Vikas Kumar, Neuropharmacology Research Laboratory, Department of Pharmaceutics, Indian Institute of Technology (Banaras Hindu University), Varanasi-22I 005, India, Tel +9l-542-6702742, Fax, +9l-542-2368428l, Email vikas.phe@iitbhu.ac.in
\end{abstract}

Received: May 29, 2015 | Published: June 29, 2015
Abbreviations: CNS, central nervous system; DMSO, dimethyl sulfoxide; HL-60, human leukemia-60; IL, interleukin; RT-PCR, reverse transcription polymerase chain reaction; TLR, toll-like receptor; TNF, tumor necrosis factor

\section{Introduction}

Andrographis paniculata (Burm. F.) Wall. Ex Nees. is a medicinal plant of Acanthaceae family widely used in both traditionally known Chinese and Indian systems of medicine as a tonic for prevention and cure of infectious disease, inflammation, fever and common cold. Andrographolide is quantitatively the major bioactive secondary metabolite of the plant, now often considered by modern drug discoverers as a structurally and functionally novel therapeutic lead potentially useful for similar purpose. ${ }^{1}$ Recent observations in our laboratories and elsewhere have revealed in addition that it is a modulator of adaptive immune responses with stress response regulating activities. ${ }^{2-4}$ Toll-like receptors (TLRs) are a class of proteins that play a key role in the innate immune system regulating the functions of all bodily organs including that of brain. They are expressed on cells of the immune system that allow for the recognition of molecular motifs of pathogenic bacteria, fungi and viruses modulating cytokine homeostasis involved in inflammatory processes. ${ }^{5}$ Cytokines are broad category of small proteins that are important in cell signaling. They are now classified in two broad categories viz. pro-inflammatory and anti-inflammatory ones. Some cytokines like IL-1, IL-1 $\beta$ and TNF- $\alpha$ are pro-inflammatory, where as others such as IL-4, IL-10 and IL-13 suppressing the activity of pro-inflammatory cytokines, are called anti-inflammatory cytokines. All these cytokines have been implicated in the pathogenesis and progression of inflammatory, neurodegenerative and other disorders caused by, or associated with, dysregulation of stress-responsive neuroendocrine and neurotransmission systems. ${ }^{6}$ Although the functions of TLR signaling pathways have been implicated in modulating effects of andrographolide and Andrographis paniculata extracts against stress triggered inflammatory and other biological responses. ${ }^{2,4}$ as yet no reports on its ability to modulate expressions of TLRs have appeared. Results of some in vitro experiments indicating that modulation of TLR-7 and TLR-8 expressions by andrographolide are involved in its anti-inflammatory and other bioactivities are summarized in this article.

\section{Materials and Methods}

\section{Drugs and chemicals}

Andrographolide (99.0\% pure by HPLC) from A. paniculata leaf extract (Figure 1) was used. The isolation and analytical characterization details are described elsewhere. ${ }^{3}$ All other chemicals and reagents used were from commercial sources.

\section{In vitro cell toxicity study}

Human Promyelocytic leukemic cell line (HL-60, NCCS Pune, India) was maintained in $10 \%$ serum supplemented Iscove's Modified Dulbecco's Medium. A density of $5 \times 10^{4}$ cells/well in a 96-well culture plate was used to assess the effect of andrographolide (10,30, 50, 100, $300 \mu \mathrm{M}$ dissolved in dimethyl sulfoxide; DMSO) on cell viability by MTT assay. In short, the viability of HL-60 cells were quantified in terms of mitochondrial metabolic activity using 4-[3-(4-iodophenyl)2-(4-nitrophenyl)-2H-5-tetrazolio]-1,3-benzene disulfonate (watersoluble tetrazolium salt-1) based colorimetric cell proliferation assay according to the manufacturers' instructions (MTT Cell Growth Assay Kit, Millipore, USA). After 24h pre-incubations, WST-1 was added to the cells and further incubated for $4 \mathrm{~h}$ under standard culture conditions. Absorbance was measured at $450 \mathrm{~nm}$ using $\mathrm{iMark}^{\mathrm{TM}}$ Microplate Reader (BioRad, USA). 


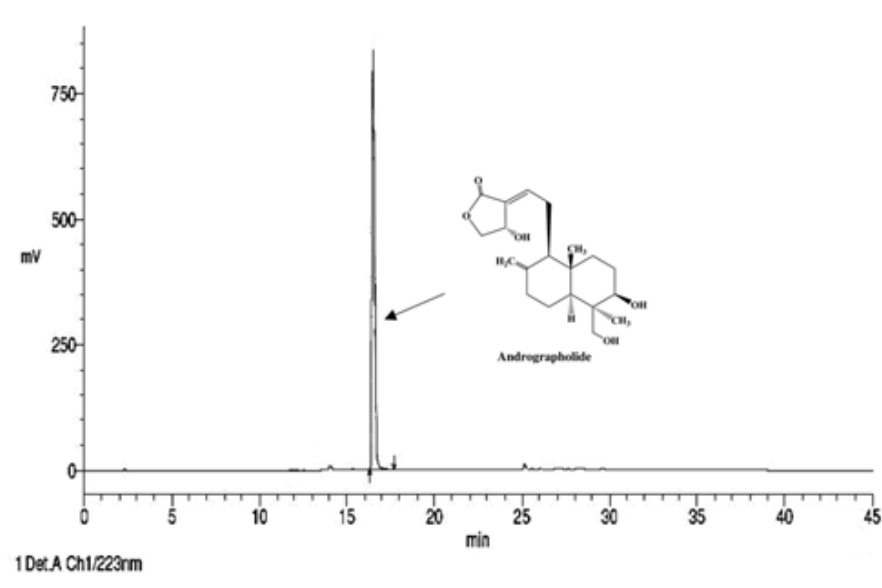

Figure I HPLC fingerprint and chemical structure of andrographolide.

\section{TLRs and cytokines expressions}

HL-60 cell line was used to assess the effect of andrographolide at $10 \mu \mathrm{M}$ concentration on expressions of toll like receptors and cytokines.

Table I Primers for RT-PCR
The HL-60 cells were cultured $\left(1 \times 10^{6} \mathrm{cells} / \mathrm{well} / \mathrm{ml}\right.$ of RPMI media) in a 24 well culture plates. Expressions of TLRs viz., TLR-3, TLR-7 and TLR- 8 and cytokines (TNF- $\alpha$, IL-1 $\beta$ and IL-10) were quantified by RT-PCR method as per manufacturers' instructions (High Capacity cDNA Reverse Transcription Kit, Applied Biosystems ${ }^{\mathrm{TM}}$, USA). The ligand of TLRs viz. polyinosinic-polycytidylic acid (Ploy I: C; $1 \mu \mathrm{g} /$ $\mathrm{ml})$, imiquimod $(8 \mathrm{mM})$, resiquimod $(\mathrm{R} 848 ; 1 \mu \mathrm{g} / \mathrm{ml})$ were used as specific agonist to trigger the expressions of TLR-3, TLR-7 and TLR8 , respectively. These agonistic ligands were dissolved in DMSO and incubated with HL-60 cells for $24 \mathrm{~h}$ at $37^{\circ} \mathrm{C}, 5 \% \mathrm{CO}_{2}$ and $95 \% \mathrm{O}_{2}$, alone or along with andrographolide. Hereupon the TLRs agonist and andrographolide were added simultaneously to the cell cultures. All mRNA sequences were retrieved from NCBI database (http://www. ncbi.nlm.nih.gov/nuccore). The gene-specific primers were designed using primer 3 software (http://fokker.wi.mit.edu/primer3) and synthesized at Integrated DNA Technologies, Inc, USA (Table 1). The PCR was carried out in a thermal cycler (Applied Biosystems, CA, USA). The density of each band was measured using densitometry software provided with AlphaImager ${ }^{\circledR}$ gel documentation system (Alpha-Imager, India). Amplifications were carried out in triplicate and the relative expression of cytokine mRNA genes was determined using $\beta$-actin housekeeping gene expression as an internal control.

\begin{tabular}{|c|c|c|c|}
\hline Gene & Primer sequence & Product size (bp) & Annealing temperature $\left({ }^{\circ} \mathrm{C}\right)$ \\
\hline TLR-3 & $\begin{array}{l}\text { Sense 5'-GCTAGCAGTCATCCAACAGA-3' } \\
\text { Antisense 5'-TTGTGGGTAGATCATCGGGT-3' }\end{array}$ & 177 & 54 \\
\hline TLR-7 & $\begin{array}{l}\text { Sense 5'-CCTTGTGCGCCGTGTAAAAA-3' } \\
\text { Antisense '5'-GGGCACATGCTGAAGAGAGT-3' }\end{array}$ & 114 & 55 \\
\hline TLR-8 & $\begin{array}{l}\text { Sense 5'-GCAAAATAGCTCCTGCAGCC-3' } \\
\text { Antisense '5'-TCTTCGGCGCATAACTCACA-3' }\end{array}$ & 120 & 55 \\
\hline TNF- $\alpha$ & $\begin{array}{l}\text { Sense 5'-TCAGAGGGCCTGTACCTCAT-3' } \\
\text { Antisense 5'-GGAGGTTGACCTTGGTCTGG-3' }\end{array}$ & 127 & 54 \\
\hline IL-10 & $\begin{array}{l}\text { Sense 5'-CGAGATGCCTTCAGCAGAGT-3' } \\
\text { Antisense 5'-CGCCTTGATGTCTGGGTCTT-3' }\end{array}$ & 189 & 56 \\
\hline IL-I $\beta$ & $\begin{array}{l}\text { Sense '5'-GCTGCTCTGGGATTCTCTTCA-3' } \\
\text { Antisense 5'-CAGGTCCTGGAAGGAGCACT-3' }\end{array}$ & 172 & 56 \\
\hline$\beta$-actin & $\begin{array}{l}\text { Sense 5'-CTCACCATGGATGATGATATCGC-3' } \\
\text { Antisense 5'-AGGAATCCTTCTGACCCATGC-3' }\end{array}$ & 163 & 55 \\
\hline
\end{tabular}




\section{Statistical analysis}

Means \pm standard error of mean (SEM) was calculated for the observed values. Statistical analysis for Figure 2A was performed by one way analysis of variance (ANOVA) followed by Student-
Newman-Keuls multiple comparison test and t-test for Figure 2B. GraphPad Prism-6 software (GraphPad Software Inc., CA, USA) was used for statistical analysis. P-values less than 0.05 were always considered as statistically significant.
(A)
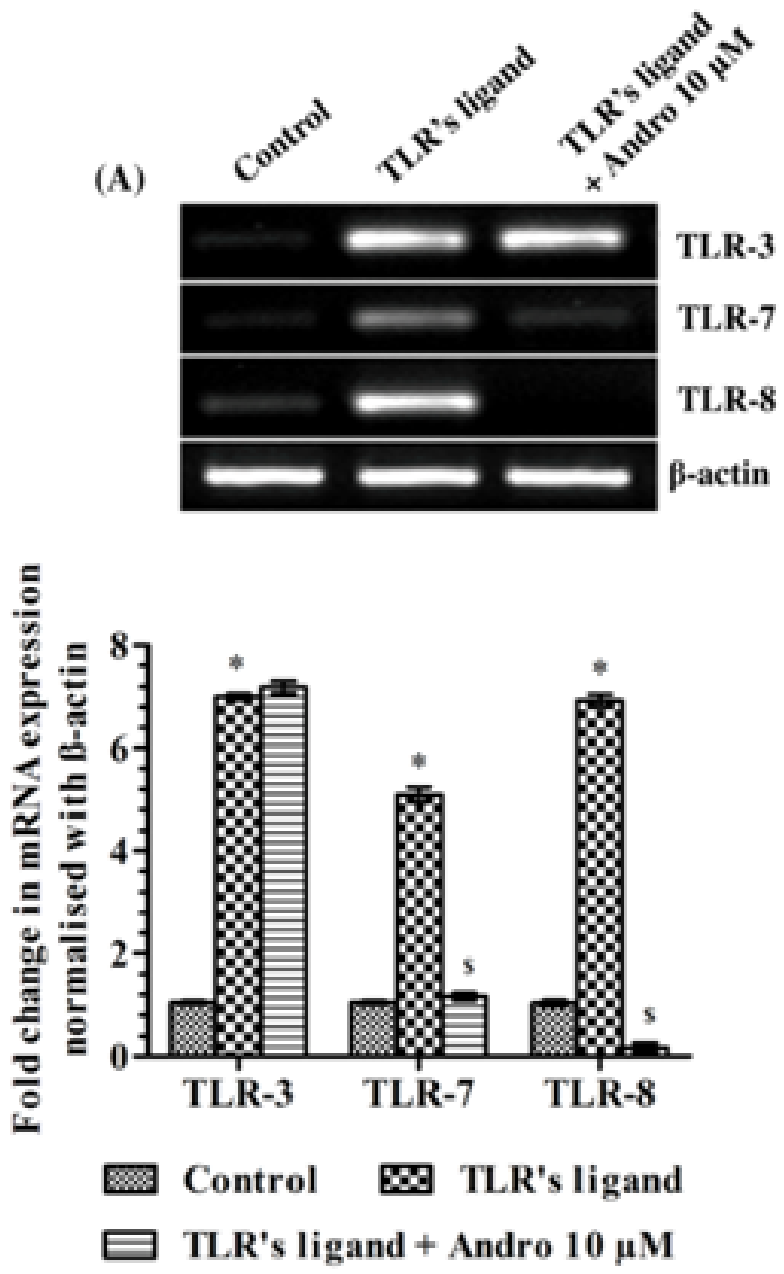

(B)
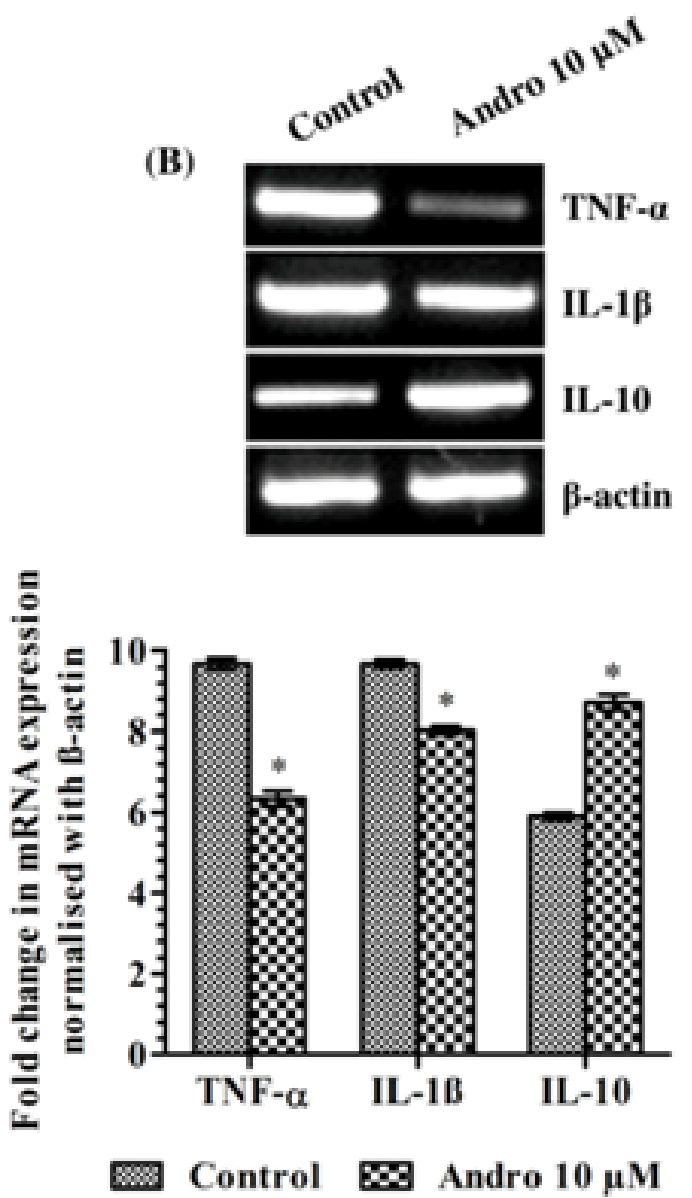

Figure 2A Effect of andrographolide on TLRs expression viz. TLR-3,TLR-7 and TLR-8.

Figure 2B Effect of andrographolide on cytokines expression viz.TNF- $\alpha$, IL-I $\beta$ and IL-I0 in HL-60 cell-line. The gel picture showing expression of TLRs and cytokines and respective histograms showed fold change in mRNA expression normalized with $\beta$-actin housekeeping gene. $*=p<0.05$ vs. control, $\$=p<0.05$ vs. TLR's ligand.Andro= Andrographolide.

\section{Results and discussion}

In cell cytotoxity experiment, $10 \mu \mathrm{M}$ andrographolide hat no effects on viability HL-60 cells and its calculated $\mathrm{IC}_{50}$ for $50 \%$ reduction of HL-60 cell viability was $38.62 \mu \mathrm{M}$. Reported $\mathrm{IC}_{50}$ value of andrographolide for its anti-inflammatory and other activities observed in this and other cell lines vary between 7 and $35 \mu \mathrm{M}^{7}$ Therefore, $10 \mu \mathrm{M}$ andrographolide was used in further experiments conducted to estimate its effects on cytokines and TLRs expressions. An experimental study examining TLRs in the central nervous system (CNS) indicates that these receptors not only play a role in innate immunity in response to infectious diseases but may also participate in CNS autoimmunity, neuro-degeneration and tissue injury. ${ }^{8}$ TLR-3 recognizes double-stranded RNA (dsRNA) released during viral infections, triggering the production of type-1 interferon and inflammatory cytokines/chemokines via the Toll/IL-1R domain- containing adaptor-inducing interferon- $\beta$ (TRIF). ${ }^{9}$ TLR-3 activation exacerbates chronic neurodegeneration ${ }^{10}$ and triggers nigrostriatal dopaminergic degeneration. ${ }^{11}$ In addition, activation of the viral innate immune receptor TLR-3 sensitizes the neonatal brain to subsequent hypoxic-ischemic damage. ${ }^{9}$ However, contradictory reports suggest that stimulation of the TRIF pathway may be neuroprotective by reprogramming the cerebral response to stroke. ${ }^{12}$ TLR-7 and TLR-8 are highly homologous to each other and are important for immune responses elicited by GU-rich ssRNA as well as synthetic chemicals, including the imidazoquinoline compounds (i.e., imiquimod and resiquimod) and guanosine analogs. ${ }^{13-15}$ The latter compounds (guanosine analogs) were initially described for their ability to activate TLR- 7 and TLR- 8 and are potent immune response modifiers leading to the production of cytokines (i.e., IFNs) that exert important antiviral and antitumor activities. ${ }^{13}$ There are also evidences that TLR7 and TLR- 8 expressed in microglia ${ }^{16,17}$ and astrocytes. ${ }^{18}$ 
Representative gel pictures showing effects of this andrographolide concentration in incubation medium on mRNA expression of TLRs and cytokines quantified in HL-60cells (normalized with $\beta$-actin as housekeeping gene) are shown in Figure 2A and Figure 2B respectively. It is apparent from the results summarized in Figure 2A that although andrographolide has no effects on TLR-3 expression in these cells, it completely suppresses the expressions of both TLR-7 and TLR-8 in them. As shown in Figure 2B, incubation of the cells with $10 \mu \mathrm{M}$ andrographolide alone significantly suppressed the expressions of the anti-inflammatory cytokines TNF- $\alpha$ and IL- $1 \beta$, whereas that of the anti-inflammatory cytokine IL-10 was significantly elevated. These results reveal that andrographolide is more effective in suppressing TLR-7 and TLR-8 expressions than suppressing the expressions of the two inflammatory cytokines studied, or for stimulating expression of the anti-inflammatory one IL-10. They could suggest that modulatory effects of andrographolide on cytokine homeostasis might as well be due to its ability to inhibit the expressions of TLR-7 and TLR-8. However, more detailed dose response studies and using different cell lines and in vivo or ex vivo experiments will be necessary to reaffirm this assertion.

It is now becoming increasingly apparent that TLR-7 and TLR-8 play important roles in the immune response to viral infection and other disorders of auto-immune system by elevating IL-6, TNF- $\alpha$ and IFN- $\beta$ secretions ${ }^{19,20}$ and that their antagonistic ligands are potential antiviral agents with diverse therapeutic potentials. ${ }^{21}$ Observations reported in this communication are the very first ones revealing its suppressing effects on TLR-7 and TLR- 8 expressions and that after its tested concentration it has no effects TLR-3 expression.

\section{Conclusion}

Since andrographolide possesses antibacterial and antiviral properties with broad spectrums of therapeutically interesting pharmacological activity profile and safety margin and beneficial effects against adverse stress responses, it seems to be another secondary plant metabolite with pleiotropic protective and curative potentially against broad spectrums of comorbidities commonly encountered in almost all chronically ill patients.

\section{Acknowledgements}

AKT thankfully acknowledged the Department of Science and Technology, Government of India, New Delhi for awarding INSPIRE Fellowship (IF110595). Thanks are also due to Natural Remedies Pvt. Ltd., Bangalore, India, for generously supplying the gift sample of pure andrographolide isolated from $A$. paniculata along with its HPLC fingerprint.

\section{Conflict of interest}

The author declares no conflict of interest.

\section{References}

1. Chandrasekaran CV, Thiyagarajan $\mathrm{P}$, Deepak $\mathrm{HB}$, et al. In vitro modulation of LPS/calcimycin induced inflammatory and allergic mediators by pure compounds of Andrographis paniculata (King of bitters) extract. International Immunopharmacology. 2011;11(1):79-84.

2. Panossian A, Wikman G. Efficacy of Andrographis paniculata in upper respiratory tract infectious diseases and the mechanism of action. In: Wagner H, et al. editors. Evidence and Rational Based Research on Chinese Drugs. Austria, USA: Springer Publisher; 2013. p. 137-179.
3. Thakur AK, Soni UK, Rai G, et al. Protective effects of Andrographis paniculata extract and pure andrographolide against chronic stresstriggered pathologies in rats. Cellular and Molecular Neurobiology. 2014;34(8):1111-1121

4. Thakur AK, Chatterjee SS, Kumar V. Adaptogenic potential of andrographolide: An active principle of the king of bitters (Andrographis paniculata). Journal of Traditional and Complementary Medicine. 2015;5(1):42-50.

5. Di Gioia M, Zanoni I. Toll-like receptor co-receptors as master regulators of the immune response. Molecular Immunology. 2015;63(2):143152 .

6. Ricci S, Fuso A, Ippoliti F, et al. Stress-induced cytokines and neuronal dysfunction in Alzheimer's disease. Journal of Alzheimer's Disease. 2012;28(1):11-24.

7. Low M, Khoo CS, Münch G, et al. An in vitro study of anti-inflammatory activity of standardised Andrographis paniculata extracts and pure andrographolide. BMC Complementary and Alternative Medicine. 2015;15:18.

8. Kielian T. Toll-like receptors in central nervous system glial inflammation and homeostasis. J Neurosci Res. 2006;83(5):711-730.

9. Stridh L, Mottahedin A, Johansson ME, et al. Toll-like receptor-3 activation increases the vulnerability of the neonatal brain to hypoxia-ischemia. J Neurosci. 2013;33(29):12041-12051.

10. Field R, Campion S, Warren C, et al. Systemic challenge with the TLR3 agonist poly I:C induces amplified IFNalpha/beta and IL-1beta responses in the diseased brain and exacerbates chronic neurodegeneration. Brain Behav Immun. 2010;24(6):996-1007.

11. Deleidi M, Hallett PJ, Koprich JB, et al. The Toll-like receptor-3 agonist polyinosinic:polycytidylic acid triggers nigrostriatal dopaminergic degeneration. J Neurosci. 2010;30(48):16091-16101.

12. Marsh B, Stevens SL, Packard AE, et al. Systemic lipopolysaccharide protects the brain from ischemic injury by reprogramming the response of the brain to stroke: a critical role for IRF3. J Neurosci. 2009;29(31):9839-9849.

13. Hemmi H, Kaisho T, Takeuchi O, et al. Small anti-viral compounds activate immune cells via the TLR7 MyD88-dependent signaling pathway. Nat Immunol. 2002;3(2):196-200.

14. Diebold SS, Kaisho T, Hemmi H, et al. Innate antiviral responses by means of TLR7-mediated recognition of single-stranded RNA. Science. 2004;303(5663):1529-1531.

15. Heil F, Hemmi H, Hochrein $\mathrm{H}$, et al. Species-specific recognition of single-stranded RNA via toll-like receptor 7 and 8. Science. 2004;303(5663):1526-1529.

16. Bsibsi M, Ravid R, Gveric D, et al. Broad expression of Toll-like receptors in the human central nervous system. J Neuropathol Exp Neurol. 2002;61(11):1013-1021.

17. Olson JK, Miller SD. Microglia initiate central nervous system innate and adaptive immune responses through multiple TLRs. J Immunol. 2004;173(6):3916-3924.

18. Carpentier PA, Begolka WS, Olson JK, et al. Differential activation of astrocytes by innate and adaptive immune stimuli. Glia. 2005;49(3):360374.

19. Triantafilou K, Vakakis E, Orthopoulos G, et al. TLR8 and TLR7 are involved in the host's immune response to human parechovirus 1. European Journal of Immunology. 2005;35(8):2416-2423. 
20. Zhu FG, Jiang W, Dong Y, et al. IMO-8400, a novel TLR7, TLR8 and TLR9 antagonist, inhibits disease development in lupus-prone NZBW/ F1 mice. The Journal of Immunology. 2012;188(1):119.12.
21. Yu Q, Huynh T, Sali A, et al. Blocking Toll-like receptor pathway using an antagonist of TLR7, 8 and 9 reduces inflammation in dystrophin deficient mdx mice (PD3.004). Neurology. 2013;80(1):PD3-004. 